\title{
Health at age 11: reports from schoolchildren and their parents
}

\author{
H Sweeting, P West
}

\begin{abstract}
Objective-To present self reports by children and reports by parents on behalf of their children relating to general health, current conditions, and recent symptoms. Design-Questionnaires completed by children and parents as part of the longitudinal "West of Scotland 11 to 16 study: teenage health."
\end{abstract}

Setting-135 primary schools in Central Clydeside.

Subjects-2586 children aged 11 years, surveyed from October 1994 to March 1995 (response rate 93\%). Questionnaires also completed by parents of $86 \%$ of the sample.

Main outcome measures-Ratings of health over the past 12 months, presence of (limiting) longstanding illness, nine current conditions, and 11 recent symptoms.

Results-Only $47 \%$ of children described their health as "good" in the previous year. Around $20 \%$ reported a longstanding illness and $8 \%$ a limiting illness; $20 \%$ reported migraine or headaches, $13 \%$ reported asthma. Recent stomach aches or sickness, colds or flu, and headaches were each reported by around $60 \%$. "Malaise" (emotional) symptoms were common. Parents reported similar levels of (limiting) longstanding illness, but rates of conditions and symptoms reported by parents were lower than reported by their children. Parent-child agreement was greatest for the presence of longstanding illness and the conditions of asthma, diabetes, and skin problems. It was lower for recent symptoms, particularly those categorised as reflecting malaise.

Conclusions-These results challenge assumptions of good health and wellbeing at this age. Illness reporting depends on various factors, including saliency, social desirability, and definitions of normality. Parent-child discrepancies may reflect different definitions of illness or symptoms; they do not mean that one should be dismissed as "wrong."

(Arch Dis Child 1998;78:427-434)

MRC Medical

Sociology Unit, 6

Lilybank Gardens,

Glasgow G12 8RZ, UK

H Sweeting

P West

Correspondence to:

Dr Sweeting.

email: helen@msoc.

mrc.gla.ac.uk

Accepted 22 December 1997 le in their teenage years, ${ }^{1}$ ce less than we do about younger children or adults. This relative neglect may arise from the "widespread but misguided belief that they are 'a fit and healthy group"'" and as such medically uninteresting. The improvement in many areas of child health during the 20th century is undeniable. Mortality under the age of 20 has fallen by over $90 \%$ since $1900,{ }^{3}$ and compared with their ancestors 90 years ago, most children are taller, better nourished, more robust, and freer from disease. ${ }^{4}$ As a result the focus of paediatric attention has moved away from the traditional infectious diseases towards long term disorders, handicap, and psychological disturbance. ${ }^{5}$

Information on health in this age group is generally limited to epidemiological surveys of specific diseases or conditions such as asthma and other respiratory symptoms, ${ }^{6-8}$ headache and migraine,${ }^{9}{ }^{10}$ or diabetes. ${ }^{11}$ Official publications that present data on child morbidity generally do so in wide age bands. For example, the United Kingdom annual General household survey shows rates of longstanding illness and NHS general practitioner consultations for ages $0-4$ and $5-15,{ }^{12}$ RCGP morbidity statistics present consultation rates for ages $0-4$ and $5-14,{ }^{13}$ while the OPCS survey of disability among children has prevalence estimates for ages $0-4,5-9$, and $10-15 .{ }^{14}$ The age bands used in these published statistics are reflected in the presentation of morbidity data in a recent book that pulls together data on the health of children. ${ }^{3}$ As we have argued previously, the wide age bands employed in large scale surveys such as these may obscure the picture concerning age based changes in health or in the determinants of health in youth. ${ }^{15}{ }^{16} \mathrm{~A}$ child aged 5 years is very different from a teenager aged 15 , and there is no reason to believe that their health problems or needs will be the same. The lack of age specific data means that children and their parents - as well as professionals - may have a poor understanding of the needs of "normal" children, and this makes health policy and planning difficult or arbitrary, based for example on what has been described as the "emotional weighting" of certain diseases. ${ }^{17}$

Health survey data on children are generally obtained from their parents-for example, General household survey interviews are confined to people aged 16 and over. While it is accepted that persons reporting their own experiences respond more fully than those by proxy, ${ }^{18}$ certain groups may be considered unreliable or inadequate informants in their own right. Children form one such group, ${ }^{19}$ although the exact age at which they cease to be unreliable may be difficult to determine. As most health care is carried out by parents, they are usually assumed to be the best proxy 
Table 1 General health: self reports by children and reports by parents about their children

\begin{tabular}{|c|c|c|c|c|c|c|}
\hline & \multicolumn{3}{|c|}{ Children's reports (\%) } & \multicolumn{3}{|c|}{ Parents'reports (\%) } \\
\hline & Boys & Girls & p value & Boys & Girls & $p$ value \\
\hline \multicolumn{7}{|l|}{ Health in the past year } \\
\hline Good & 47.7 & 47.5 & & 77.1 & 79.3 & \\
\hline Fairly good & 49.0 & 50.2 & & 21.7 & 19.4 & \\
\hline Not good & 3.3 & 2.3 & 0.25 & 1.2 & 1.3 & 0.37 \\
\hline \multicolumn{7}{|l|}{ Longstanding illness } \\
\hline None & 79.5 & 82.5 & & 77.7 & 83.2 & \\
\hline Illness, not limiting & 11.7 & 10.4 & & 16.2 & 9.9 & \\
\hline Illness, limiting & 8.9 & 7.0 & 0.11 & 6.2 & 6.9 & $<0.001$ \\
\hline
\end{tabular}

informants of childhood illness. Daily monitoring of a child's wellbeing alerts parents to small behavioural changes or physical symptoms; they (usually mothers) “... make daily decisions regarding (their children's) wellbeing, (and) recognise the early stages of their illness ..."20

However, definitions and reporting of change or illness are not immutable, but may vary in several ways. The first of these has been described by Mechanic and Newton as "the saliency rule"; the more salient an illness, the more accurately will it be reported. For example, serious disorders-those that require repeated attention or have received recent attention-will be better reported, in contrast to those that are less persistent or are ill defined. In respect of proxy reporting, it is obvious that certain less visible symptoms or disorders-for example, psychological distress-may not be reported unless the subject has complained about them. ${ }^{21}$ In addition to saliency, illness reporting is also subject to "censorship" governed by normative ideas about medical relevance and social desirability. ${ }^{22}$ Thus a mother's report of her child's symptoms will be based on whether she defines it as reaching a minimum requirement of seriousness, which in turn may be affected by factors such as the child's age or the season of the year. Sensitivity to social threat or embarrassment may lead to reduced reporting of certain conditions or symptoms. Finally, there is evidence that symptom reporting is associated with stress. Mothers under stress not only reported more illness symptoms for themselves, but also for their children, and were more likely to telephone a doctor about their children's health (data to show whether these children actually had more symptoms were unavailable). ${ }^{23}$

In this paper we present data on a variety of indicators of health from a school based sample of 11 year old children. We had two main aims. The first was to present basic health data in the form of self reports by children and reports by parents on behalf of their children relating to general health, current conditions, and recent symptoms at age 11 . For informative purposes, data for boys and girls are presented separately in the tables (together with the significance levels of any differences), but as sex differences are not the focus of the paper they are not commented on. Our second aim was to compare the reports of children and their parents. Comparison of answers to an identical set of questions allows us to establish the degree of concordance between responses, and hence definitions of illness. Although this was largely an exploratory study, previous reports allowed us to test the hypothesis that child-parent agreement over a particular condition or symptom will be greater in the following instances:

- The more severe it is (for example, conditions that require continued monitoring or treatment)

- The more apparent it is (for example, skin conditions)

- The more stable it is (we hypothesise greater agreement about conditions than related recent symptoms).

\section{Methods}

BACKGROUND, SAMPLE, AND METHODS

The data are taken from the first sweep of the "West of Scotland 11 to 16 study: teenage health". This is a longitudinal, school based survey of health and health behaviours in a cohort of children resident in the Central Clydeside conurbation, a predominantly urban area in and around Glasgow city with a population of 1.6 million and standardised mortality ratio (relative to Scotland as a whole) of 109 in $1992 .{ }^{24}$ The sample is representative and random because of the general need to make inferences to the population of this age group. The children were recruited in their final year of primary school (Scottish primary 7, aged 11-12) and are being followed through the transition to secondary school until the end of statutory education (Scottish secondary 4, aged 15-16), with one intermediate contact (aged 13-14).

To ensure a representative random sample of children at both the primary and secondary school stages, taking into account the vagaries of the transition process (increasing parental choice has diminished the traditional links between local associated primary and secondary schools), the sampling scheme comprised several steps. First, a random sample of $43 \mathrm{sec}-$ ondary schools was selected, stratified on the basis of geographical location (educational division), denominational status (Catholic or non-denominational), and deprivation (the proportion of pupils in receipt of a clothing

Table 2 Current conditions: self reports by children; reports by parents about their children; child:parent ratio

\begin{tabular}{|c|c|c|c|c|c|c|c|c|}
\hline & \multicolumn{3}{|c|}{ Children's reports (\%) } & \multicolumn{3}{|c|}{ Parents' reports (\%) } & \multicolumn{2}{|c|}{ Child:parent ratio } \\
\hline & Boys & Girls & $p$ value & Boys & Girls & $p$ value & Boys & Girls \\
\hline Allergies & 23.9 & 23.4 & 0.75 & 12.5 & 9.4 & 0.02 & 1.9 & 2.5 \\
\hline Migraines, frequent headaches & 21.0 & 19.7 & 0.40 & 8.1 & 8.7 & 0.59 & 2.6 & 2.3 \\
\hline Skin problems, eczema, acne & 13.8 & 19.3 & $<0.001$ & 9.1 & 12.8 & 0.004 & 1.5 & 1.5 \\
\hline Wheezy chest, bronchitis & 16.3 & 11.3 & $<0.001$ & 7.4 & 5.6 & 0.10 & 2.2 & 2.0 \\
\hline Asthma & 15.7 & 9.9 & $<0.001$ & 13.5 & 8.1 & $<0.001$ & 1.2 & 1.2 \\
\hline Fits, convulsions, epilepsy & 0.5 & 1.0 & 0.19 & 0.4 & 0.2 & 0.41 & 1.2 & 5.0 \\
\hline Diabetes & 0.3 & 0.2 & 0.47 & 0.3 & 0.1 & 0.32 & 1.0 & 2.0 \\
\hline
\end{tabular}


Table 3 Symptoms in the past month: self reports by children; reports by parents about their children; child:parent ratio

\begin{tabular}{|c|c|c|c|c|c|c|c|c|}
\hline & \multicolumn{3}{|c|}{ Children's reports (\%) } & \multicolumn{3}{|c|}{ Parents'reports (\%) } & \multicolumn{2}{|c|}{ Child:parent ratio } \\
\hline & Boys & Girls & $p$ value & Boys & Girls & p value & Boys & Girls \\
\hline \multicolumn{9}{|l|}{ Physical } \\
\hline Stomach ache or sickness & 56.6 & 65.6 & $<0.001$ & 32.9 & 40.7 & $<0.001$ & 1.7 & 1.6 \\
\hline Cold or flu & 51.8 & 62.8 & $<0.001$ & 41.8 & 46.0 & 0.05 & 1.2 & 1.4 \\
\hline Headache & 47.9 & 57.6 & $<0.001$ & 34.7 & 45.0 & $<0.001$ & 1.4 & 1.3 \\
\hline Aching back, legs or arms & 38.7 & 33.0 & 0.003 & 17.8 & 17.8 & 0.99 & 2.2 & 1.8 \\
\hline Spots, rashes, skin problems & 20.6 & 30.6 & $<0.001$ & 14.3 & 22.4 & $<0.001$ & 1.4 & 1.4 \\
\hline Felt dizzy or faint & 20.7 & 17.7 & 0.06 & 6.0 & 9.8 & 0.001 & 3.4 & 1.8 \\
\hline Asthma or wheezy chest & 18.7 & 15.1 & 0.02 & 12.7 & 9.1 & 0.007 & 1.5 & 1.7 \\
\hline \multicolumn{9}{|l|}{ Malaise } \\
\hline Nervous, worried or anxious & 38.7 & 44.8 & 0.002 & 17.6 & 18.7 & 0.53 & 2.2 & 2.4 \\
\hline Irritable or bad tempered & 43.2 & 37.7 & 0.004 & 30.5 & 35.2 & 0.02 & 1.4 & 1.1 \\
\hline Difficulty getting to sleep & 38.2 & 35.8 & 0.21 & 13.5 & 15.5 & 0.17 & 2.8 & 2.3 \\
\hline Been sad, unhappy or low & 33.0 & 36.7 & 0.04 & 18.2 & 22.6 & 0.01 & 1.8 & 1.6 \\
\hline
\end{tabular}

grant), together with a separate stratum of independent schools. Second, a sample of primary schools was selected on the basis of the secondary school sample, stratified on the proportion of pupils in receipt of a clothing grant, and taking account of the proportion of pupils transferring both into the selected secondaries (from associated primary schools and through parental placing requests) and out of them (from selected primary schools to other secondaries). Finally, within each selected primary school, classes (whole or composite) were randomly selected. Children who were attending the selected secondary schools at the time of the age 13-14 years survey sweep constitute the sample (thus several children surveyed at age 11 were lost and do not form part of this final sample, even at baseline). Further details of the sample design are available. ${ }^{25}$

At the primary 7 stage, the final sample comprised 2586 children (1339 boys and 1247 girls) surveyed in 135 primary schools. This is a response rate of $93 \%$ of target children, average age 11 years 3 months (standard deviation 4 months). Classroom sessions were held from October 1994 to March 1995, during which the children completed questionnaires on health, self esteem and self image, health related behaviours and attitudes, family life, school, leisure activities, friends, and projections for the future. Nurses conducted a short interview with each child about longstanding illness, current conditions, and parental occupation, and recorded their height, weight, and respiratory function. Questionnaires about earlier health history and family background, delivered by children to their parents, were completed and returned by way of the school in $86 \%$ of the sample.
MEASURES

This paper is based on health related measures obtained from children and parents.

\section{Ratings of general health}

Nurses asked children two standard items from the United Kingdom General household survey ${ }^{12}$ : whether their health over the past 12 months had, on the whole, been good, fairly good, or not good (collapsed for the majority of the current analyses into "good" $v$ "fairly" or "not good"); and whether they had any longstanding illness, disability, or infirmity and, if so, whether it limited their activities (collapsed into longstanding illness present or absent). The parental questionnaire contained identical items to the child questionnaire.

\section{Current conditions}

Nurses asked children whether they currently had any of the following seven conditions: diabetes; fits, convulsions, or epilepsy; asthma; migraine or frequent headaches; skin problems such as eczema, acne, or psoriasis; allergies; and wheezy chest or bronchitis. The parental questionnaire presented the same list, and asked whether the child had ever, or currently, suffered from each condition.

\section{Recent symptoms}

The children's questionnaire presented a list of 11 symptoms from which they indicated any that they had experienced in the previous month. The parental questionnaire contained an identical list to the child questionnaire. In this paper each symptom is categorised as either "physical" (stomach ache or sickness; cold or flu; headache; aching back, legs or arms; spots, rashes or skin problems; felt dizzy or faint; asthma or wheezy chest) or "malaise"

Table 4 Health in the past year and longstanding illness: cross tabulations of children's and parents' responses

\begin{tabular}{llllll}
\hline & & \multicolumn{2}{l}{ Children's responses } \\
\cline { 3 - 6 } & Parents' responses & Boys & & \multicolumn{2}{l}{ Girls } \\
\hline Health in the past year & & Good & Fairly or not good & Good & Fairly or not good \\
& Good & $39.1 \%(436)$ & $38.1 \%(425)$ & $40.6 \%(451)$ & $38.8 \%(432)$ \\
& Fairly or not good & $8.2 \%(91)$ & $14.7 \%(164)$ & $6.7 \%(75)$ & $13.8 \%(154)$ \\
& & Yes & No & Yes & No \\
Longstanding illness & Yes & $12.8 \%(143)$ & $9.5 \%(106)$ & $9.8 \%(109)$ & $7.1 \%(79)$ \\
& No & $8.1 \%(90)$ & $69.6 \%(777)$ & $8.4 \%(93)$ & $74.6 \%(827)$ \\
\hline
\end{tabular}


Table 5 General health and longstanding illness: $\kappa$ statistic; \% agreement in reports by children and parents

\begin{tabular}{|c|c|c|c|c|c|c|c|c|}
\hline & \multicolumn{3}{|l|}{ Boys } & \multicolumn{3}{|l|}{ Girls } & \multicolumn{2}{|c|}{ Agreement (\%) } \\
\hline & $\kappa$ & $\begin{array}{l}95 \% \text { confidence } \\
\text { interval }\end{array}$ & & $\kappa$ & $\begin{array}{l}95 \% \text { confidence } \\
\text { interval }\end{array}$ & & Boys & Girls \\
\hline Health in past year & 0.102 & 0.055 to 0.149 & Poor & 0.116 & 0.071 to 0.161 & Poor & 53.8 & 54.4 \\
\hline Longstanding illness & 0.481 & 0.419 to 0.543 & Moderate & 0.465 & 0.396 to 0.534 & Moderate & 82.4 & 84.4 \\
\hline
\end{tabular}

(nervous, worried or anxious; irritable or bad tempered; difficulty getting to sleep; been sad, unhappy or low). We have acknowledged that such a distinction is somewhat arbitrary-not only might symptoms such as sleep problems result from pain or other physical disorders, but those who are depressed or anxious might report more "physical" symptoms. ${ }^{26}$

\section{ANALYSES}

The measure of agreement between children and parents about identical (categorical) items is represented by the $\kappa$ statistic, with a value of 1.00 when agreement is perfect and 0.00 when agreement is no better than chance, with negative values showing worse than chance agreement. The advantage of $\kappa$ over simply examining the proportion of the sample in agreement is that while the latter is strongly influenced by relative rates (for example, simple agreement on an extremely rare condition will be high as there is a high chance of both parents and children agreeing that the condition is not present), $\kappa$ corrects for chance expected agreement. ${ }^{27}{ }^{28}$ In addition, as $95 \%$ confidence intervals can be calculated, significantly different $\kappa$ values can be identified.

The following guidelines have been suggested as an aid to interpretation of $\kappa^{2930}$ : $<0.20=$ poor, $0.21-0.40=$ fair, $0.41-0.60=$ moderate, $0.61-0.80=$ good, $0.81-1.00=$ very good.

Overall rates for each of the health measures are presented for all children and all parents (in respect of their children) in the sample. Analyses of agreement between parents and children are, however, by definition restricted to the $86 \%$ of the sample for whom a parental questionnaire was available. It is possible that this group is not representative of the sample as a whole. Children whose parents had not completed the parental questionnaire were therefore compared with those whose parents had completed it for each of the health measures described in this paper. They were found to be significantly different (significance of $\chi^{2}$ statistic of 0.05 or higher) in three of the 20 comparisons made, being more likely to describe themselves as suffering from fits, convulsions, or epilepsy, and as having had a cold or 'flu in the past month, but less likely to report allergies.

\section{Results}

REPORTED RATES: CHILDREN'S AND PARENTS' REPORTS

Ratings of general health

Table 1 shows reports of health in the past year and longstanding illness (percentages, along with the significance of any male-female difference) made by children about themselves and by parents in respect of children. Just under half the children described their health as having been "good" over the past year, half as "fairly good," and a very small proportion as "not good." Around 20\% reported a longstanding illness, with $9 \%$ of boys and $7 \%$ of girls saying it limited their activities. Although parents were much more likely to describe their child's health as having been "good" than were the children themselves, the proportions of children and parents reporting longstanding illness were very similar.

\section{Current conditions}

Table 2 shows that allergies were the condition most frequently experienced, reported by a quarter of the children, followed by migraines or headaches, described by a fifth, while skin problems, wheeze, or bronchitis and asthma each occurred in around one in six children. (Not surprisingly, there was considerable overlap in the reporting of wheeze and asthma, with over $60 \%$ of those children who reported one also reporting the other.) Convulsions or epilepsy and diabetes were, as expected, much less common, mentioned by fewer than $1 \%$ of the sample. The pattern of parents' reports about their children's current conditions was different from that of the children themselves. Allergies, skin problems, and asthma were each reported by around $11 \%$ of parents, migraines or headaches by $8 \%$, and wheezy chest or bronchitis by $6 \%$. Convulsions or epilepsy and

Table 6 Current conditions: $\kappa$ statistic; \% agreement in reports by children and parents; numbers in each cell

\begin{tabular}{|c|c|c|c|c|c|c|c|c|c|c|}
\hline & \multicolumn{3}{|l|}{ Boys } & \multicolumn{3}{|l|}{ Girls } & \multicolumn{2}{|c|}{$\begin{array}{l}\text { Agreement } \\
(\%)\end{array}$} & \multicolumn{2}{|c|}{ Numbers in each cell ${ }^{\star}$} \\
\hline & $\kappa$ & $95 \% C I$ & & $\kappa$ & $95 \% C I$ & & Boys & Girls & Boys & Girls \\
\hline Allergies & 0.326 & 0.261 to 0.391 & Fair & 0.314 & 0.251 to 0.377 & Fair & 79.3 & 79.8 & $89 ; 791 ; 48 ; 182$ & $77 ; 811 ; 28 ; 196$ \\
\hline Migraines, frequent headaches & 0.291 & 0.220 to 0.362 & Fair & 0.292 & 0.221 to 0.363 & Fair & 82.4 & 82.1 & $58 ; 859 ; 31 ; 165$ & $60 ; 851 ; 36 ; 162$ \\
\hline Skin problems, eczema, acne & 0.511 & 0.433 to 0.589 & Moderate & 0.496 & 0.429 to 0.563 & Moderate & 90.0 & 86.0 & $72 ; 927 ; 29 ; 82$ & $105 ; 847 ; 38 ; 117$ \\
\hline Wheezy chest, bronchitis & 0.324 & 0.248 to 0.400 & Fair & 0.451 & 0.361 to 0.541 & Moderate & 85.5 & 91.2 & $52 ; 895 ; 29 ; 132$ & $47 ; 964 ; 15 ; 82$ \\
\hline Asthma & 0.852 & 0.809 to 0.895 & Very good & 0.862 & 0.809 to 0.915 & Very good & 96.2 & 97.7 & $146 ; 926 ; 5 ; 37$ & $87 ; 998 ; 3 ; 22$ \\
\hline Fits, convulsions, epilepsy & -0.004 & -0.006 to -0.002 & Poor & 0.362 & -0.001 to 0.725 & Fair & 99.3 & 99.4 & $0 ; 1104 ; 4 ; 4$ & $2 ; 1101 ; 0 ; 7$ \\
\hline Diabetes & 1.000 & 1.000 to 1.000 & Very good & 0.666 & 0.051 to 1.281 & Good & 100.0 & 99.9 & $3 ; 1110 ; 0 ; 0$ & $1 ; 1107 ; 0 ; 1$ \\
\hline
\end{tabular}

*Order: child and parent agree condition present; child and parent agree condition absent; child reports condition absent, parent present; child reports condition present, parent absent.

$\mathrm{CI}$, confidence interval. 
diabetes were reported by fewer than $1 \%$ of parents. Comparison of the reports of children and parents reveals a similar picture to that relating to general health: all except one condition-diabetes-were reported by a larger proportion of children than parents. With the exception of epilepsy or convulsions in girls, the child excess was greatest for migraines or headaches, allergies, and wheezy chest or bronchitis. It was least, apart from diabetes, for asthma.

\section{Recent symptoms}

Given that this is a group of school aged children, a high prevalence of minor infections might be expected. This is borne out in table 3, the most common recent symptoms being stomach problems and colds, each reported to have occurred in the past month by around $60 \%$ of children. In addition, half the children reported headaches, a third aching limbs, a quarter skin problems, and one in five dizziness or asthma. Perhaps more of a surprise is the fact that each of the malaise symptoms was described by a third or more of the childrenfor example, nervousness and irritability were each reported by about $40 \%$. Although each symptom was also reported by fewer parents than children, about $40 \%$ of parents described stomach problems, 33\% irritability, and 20\% aching limbs, skin problems, nervousness, or sadness in their children. Most symptoms were around 1.5 times more likely to be endorsed by children than parents, but the discrepancy in rates was even greater for nervousness and sleep difficulties, and (boys only) aching limbs and dizziness.

AGREEMENT BETWEEN CHILDREN AND PARENTS The results from children and parents have thus far been compared in terms of overall proportions of the sample responding in a certain way; however, this does not tell us whether it is the same children. To look for agreement, we must cross tabulate children's and parents' responses. When this is done, as shown in table 4 , the picture becomes more complicated.

Ratings of general health

Table 4 presents cross tabulations of children's and parents' responses about the child's health in the past year ("good" $v$ "fairly good" or "not good") and longstanding illness (present $v$ absent) for boys and girls separately. Taking health in the past year for boys as an example, $39.1 \%$ of the overall sample agree on the rating of "good," and $14.7 \%$ on the ratings of "fairly good" or "not good." Adding these figures together shows that for about $54 \%$ of the sample, parents and their male children agree. However, in $8.2 \%$ of cases, boys rated their health as having been good but parents did not, while $38.1 \%$ of the boys gave their health a poorer rating than their parents. Table 5 shows two measures of agreement (the $\kappa$ statistic with $95 \%$ confidence intervals, and the percentage of the sample where agreement between parents and children occurred) for ratings of health in the past year and longstanding illness. The $\kappa$ value for agreement between parents and their male children for health in the past year was 0.102 (poor). Agreement on longstanding illness was considerably better, 0.481 (moderate). Almost identical results were obtained for girls for both $\kappa$ values and the percentage of the sample where agreement between parents and their children occurred.

\section{Current conditions}

Table 6 shows the $\kappa$ statistic with $95 \%$ confidence intervals, the percentage of the sample where agreement between parents and children occurred over the presence of conditions, and the numbers in each of the four cells: child and parent agree condition present; child and parent agree condition absent; child reports condition absent but parent that condition present; and child reports condition present but parent that condition absent. Two points are well illustrated by this table. First, as the conditions are ordered according to reported prevalence, it shows the relation of percentage agreement to overall rates. Second, showing the total in each agree/disagree cell emphasises that for some conditions the number involved was extremely small. Table 6 shows that for only one condition, asthma, did parent-child agreement achieve a very good $\kappa$ value for both boys and girls. Most $\kappa$ values were in the fair or moderate ranges. No boys and parents agreed on the presence of convulsions or epilepsy: in four cases the boys said the

Table 7 Symptoms in the past month: $\kappa$ statistic; \% agreement in reports by children and parents; numbers in each cell

\begin{tabular}{|c|c|c|c|c|c|c|c|c|c|c|}
\hline & \multicolumn{3}{|l|}{ Boys } & \multicolumn{3}{|l|}{ Girls } & \multicolumn{2}{|c|}{$\begin{array}{l}\text { Agreement } \\
(\%)\end{array}$} & \multicolumn{2}{|l|}{ Numbers in each cell $^{*}$} \\
\hline & $\kappa$ & $95 \% C I$ & & $\kappa$ & $95 \% C I$ & & Boys & Girls & Boys & Girls \\
\hline \multicolumn{11}{|l|}{ Physical } \\
\hline Stomach ache or sickness & 0.195 & 0.145 to 0.245 & Poor & 0.167 & 0.116 to 0.218 & Poor & 58.3 & 56.0 & $257 ; 390 ; 107 ; 356$ & $346 ; 277 ; 107 ; 383$ \\
\hline Cold or flu & 0.269 & 0.214 to 0.324 & Fair & 0.247 & 0.194 to 0.300 & Fair & 63.4 & 61.6 & $311 ; 393 ; 154 ; 253$ & $386 ; 299 ; 126 ; 300$ \\
\hline Headache & 0.302 & 0.247 to 0.357 & Fair & 0.332 & 0.279 to 0.373 & Fair & 65.8 & 66.0 & $261 ; 470 ; 125 ; 254$ & $383 ; 354 ; 118 ; 260$ \\
\hline Aching back, legs or arms & 0.138 & 0.085 to 0.191 & Poor & 0.239 & 0.180 to 0.298 & Fair & 62.8 & 70.5 & $111 ; 587 ; 87 ; 326$ & $116 ; 668 ; 82 ; 246$ \\
\hline Spots, rashes, skin problems & 0.299 & 0.230 to 0.368 & Fair & 0.332 & 0.271 to 0.393 & Fair & 79.9 & 73.9 & $80 ; 809 ; 79 ; 145$ & $147 ; 676 ; 102 ; 188$ \\
\hline Felt dizzy or faint & 0.157 & 0.092 to 0.222 & Poor & 0.282 & 0.210 to 0.354 & Fair & 80.1 & 82.7 & $34 ; 856 ; 33 ; 188$ & $57 ; 863 ; 51 ; 141$ \\
\hline Asthma or wheezy chest & 0.598 & 0.533 to 0.663 & Moderate & 0.565 & 0.493 to 0.637 & Moderate & 89.3 & 90.7 & $115 ; 877 ; 26 ; 93$ & $83 ; 927 ; 19 ; 85$ \\
\hline \multicolumn{11}{|l|}{ Malaise } \\
\hline Nervous, worried or anxious & 0.121 & 0.068 to 0.174 & Poor & 0.123 & 0.074 to 0.172 & Poor & 63.1 & 58.9 & $102 ; 597 ; 94 ; 315$ & $126 ; 530 ; 82 ; 376$ \\
\hline Irritable or bad tempered & 0.180 & 0.123 to 0.237 & Poor & 0.182 & 0.123 to 0.241 & Poor & 61.4 & 62.0 & $191 ; 491 ; 148 ; 281$ & $195 ; 495 ; 198 ; 224$ \\
\hline Difficulty getting to sleep & 0.133 & 0.084 to 0.182 & Poor & 0.233 & 0.178 to 0.288 & Fair & 64.1 & 69.2 & $88 ; 625 ; 62 ; 337$ & $114 ; 657 ; 59 ; 284$ \\
\hline Been sad, unhappy or low & 0.125 & 0.068 to 0.182 & Poor & 0.169 & 0.112 to 0.226 & Poor & 66.0 & 64.9 & $93 ; 639 ; 109 ; 269$ & $130 ; 592 ; 121 ; 270$ \\
\hline
\end{tabular}

Order: child and parent agree symptom present; child and parent agree symptom absent; child reports symptom absent, parent present; child reports symptom present, parent absent.

CI, confidence interval. 
condition was present but their parents said not, vice versa in another four cases, and in the remainder of the sample there was agreement on its absence (parent-child agreement thus worse than expected by chance). Among the girls, in two cases there was agreement on the presence of convulsions, in seven cases the girls said the condition was present but their parents said not, while in the remainder of the sample there was agreement on its absence. For diabetes there was perfect agreement among boys and their parents-in three cases that the condition was present, in the remainder that it was not. Among the girls, in one case there was agreement on the presence of diabetes, in another the girl said the condition was present but her parents said not, in the remainder of the sample there was agreement on its absence.

Recent symptoms

Table 7 shows that agreement on recent symptoms was even poorer, the $\kappa$ statistic only achieving moderate values for asthma. Worthy of note is the fact that while it tended to be poorest for the malaise symptoms, $\kappa$ values within the physical symptom group do not appear to be strongly related to a symptom's visibility. Thus parent-child agreement on the presence of headache was similar to that on skin problems and significantly higher (refer to $95 \%$ confidence intervals) than that on stomach ache or sickness.

\section{Discussion}

It is somewhat paradoxical that while the overall health of children has improved dramatically over the past century, only half of this group of 11 year olds rated their own health as good. However, these results accord with those from a recent study that found high levels of poor physical and mental health in an older group of adolescents followed up between the ages of 15 and $21 .{ }^{31}$ In the present study, a longstanding illness was reported by one in five children and parents, and a limiting longstanding illness by around $8 \%$ - figures that exactly match those obtained in respect of both longstanding and limiting longstanding illness in 5-15 year olds in the 1995 General household survey. ${ }^{12}$

Over the preceding 20 years of this survey, rates of longstanding illness doubled for this age group $(10 \%$ reported longstanding illness in $1975^{12}$ ). This trend may have resulted from changed expectations of health and definitions of illness resulting from increased access to medical care. ${ }^{3}$ However, it may also reflect a real increase in the prevalence of certain chronic conditions. The prevalence of asthma (this condition was reported by $13 \%$ of children and $11 \%$ of parents in the present study) is rising, whether owing to an increase in parental awareness of symptoms and subsequent initiation of health service contact, an increasing severity of the disorder, or the impact of environmental factors. ${ }^{32}{ }^{33}$ In a questionnaire survey completed in 1994 by the parents of Aberdeen schoolchildren (mean age 10.9 years) wheeze in the past three years was reported by $25.4 \%$, and a diagnosis of asthma by $19.6 \% .^{8}$ Twenty years previously, the prevalence of asthma in Aberdeen primary schoolchildren was reported to be $4.8 \% .^{34}$ There are also some indications that in northern Europe and North America there has been an increase in the prevalence of insulin dependent diabetes mellitus (reported by $0.2 \%$ of both the children and parents in the sample), the third most frequent severe chronic disease of childhood, after asthma and cerebral palsy. ${ }^{11}$ Among a representative sample of the population of England, Scotland, and Wales born in 1958 (the national child development survey), the cumulative prevalence of diabetes at age 11 was reported as $0.58 / 1000^{35}$; in $1984-5$ the overall prevalence of diabetes among white children aged 10-15 years living in Leicester was $1.87 / 1000 .^{36}$

The prevalence of the above conditions among the present sample appears to be in line with previous studies. Reports that would allow comparisons of the other conditions and symptoms in our survey are sparse or nonexistent; however, available information on migraine and headaches does suggest higher levels of reporting in the present sample. Migraines or frequent headaches were reported by $20 \%$ of children and $8 \%$ of parents, a headache in the past month by $53 \%$ children and $40 \%$ parents. A survey conducted in a United Kingdom urban general practice found that in 9-11 year olds the prevalence of migraine with aura was approximately $3 \%$, of migraine without aura 3-7\% (depending on diagnostic criterion), and of headache in the past month $30 \% .{ }^{9}$ In a self report questionnaire conducted in Sweden, $21 \%$ of 11 year olds reported experiencing a headache monthly or more often. $^{37}$

Not only were physical symptoms common among our sample, but so were symptoms of malaise - irritability, anxiety, and unhappiness. Again, this runs counter to assumptions of youthful healthiness, and to the fact that children are often characterised as "somatisers"-for example, manifesting anxiety by abdominal pain or sleep disturbance. ${ }^{38}$ While we do not suggest that these symptoms will necessarily correspond to diagnosable disorders in every case, they do represent a considerable degree of negative affect. These rates are consistent with findings from other surveys, which together suggest a one year prevalence rate for child psychiatric disorder in the general population of "around $10 \%$, but much goes unrecognised," while " $20 \%$ of primary and secondary school age children have emotional and behavioural problems." ${ }^{39}$ There is evidence of substantial increases in psychosocial disorders among young people over the past 50 years, a pattern that is not a continuation of earlier established trends. ${ }^{40}$ While the explanations will differ according to disorder, Rutter and Smith ${ }^{41}$ suggest the following: changes in family life; the increasingly fragmented, lengthy, and uncertain nature of the child-adult transition, coupled with an emphasis on peer group and youth culture; the media; and differences in moral concepts 
and values, particularly the shift towards individualisation and a rise in expectations.

Parents were generally less likely to report both conditions and symptoms than the children themselves. It could be concluded from this that children's self ratings are simply "wrong," but this is not what would be inferred if the same results occurred in adults. ${ }^{18}$ This leads to the question of when children may be deemed capable of responding adequately. Interestingly, while the Children (Scotland) Act, 1995 presumes that a child of 12 years or older is capable of forming a view, ${ }^{42}$ paediatricians generally accept that parents will make the major decisions affecting a child. ${ }^{43}$

If the discrepancies observed simply reflected random errors by the children, then there should be no patterning of the amount of agreement between them and their parents. However, the highest $\kappa$ values (those that could be categorised as reflecting at least a moderate degree of agreement) occurred in relation to the presence of longstanding illness and the conditions of asthma, diabetes, and skin problems. The lowest levels of child-parent agreement (apart from that relating to convulsions or epilepsy between parents and their male children) occurred for sadness and anxiety. In support of our initial hypothesis, parents and children were most likely to agree on conditions that are common, visible, or diagnosed. The fact that agreement did not occur for epilepsy may have resulted from the children (or parents) simply failing to understand the question, or being confused over the categorisation of febrile convulsions, child sufferers not defining themselves as such, perhaps because of a lengthy time interval since their last seizure, or because parents of sufferers did not define them as such - perhaps because of the stigma that continues to be associated with the disorder. The point is that there is no single concept of epilepsy. ${ }^{44}$

Mild symptoms are part of everyday living. Thus symptoms (or even conditions) will only be reported if they are perceived as deviations from normal. ${ }^{21}$ As Cartwright points out, "Any statement or assessment of illness is likely to be subjective and therefore to depend on the attitude of the informant." ${ }^{45}$ Evaluations of overall health or of particular symptoms tend not to be categorical, but are instead a matter of degree: how "good" is "good health," how much does a head have to ache for it to signify as a headache? Any categorisations are therefore arbitrary, and if the cut offs used by children (who are, after all, the subjects) differ from those of their parents, then disagreements that reflect real differences in illness definition will occur. Given the often quoted WHO definition of health as a "state of complete physical, mental and social wellbeing and not merely the absence of disease or infirmity," 46 such differences are entirely plausible.

Parents and children were least likely to agree on a child's emotional state. Again, this accords with our initial hypotheses, as affect may fluctuate, and may not be directly observable. In addition, high levels of disagreement may occur because a child chooses to hide feel-

\section{Key messages}

- Self reported health, conditions, and symptoms at age 11, and reports from parents on behalf of children, run counter to any assumption of youthful healthiness.

- Symptoms of malaise, such as irritability, anxiety, and unhappiness, were each reported by over one third of children.

- Parents were less likely to report both conditions and symptoms than children themselves.

- Parent-child agreement was highest for conditions that are common, visible, or diagnosed. Greatest disagreement occurred in respect of a child's emotional state.

ings from parents, or because parents are unable or unwilling to recognise emotional distress in their child. Both parents, and even more so children, are aware of the "nutty" stigma of admitting to psychological distress. As Cox notes, parents (in a child mental health setting) "often feel guilty or responsible for their child's developmental, emotional or behavioural difficulties." ${ }^{47}$ That young people are shy, concerned about issues of confidentiality, and sensitive to the attitudes of others have all been cited as reasons for their generally low consultation rates. ${ }^{2}$ By collecting data such as these, not only can the health needs of this age group be established, but a greater understanding of the health of "normal" children may also be achieved. ${ }^{1}$ These data cannot tell us the "truth" as we lack an objective external criterion against which to validate these questionnaire based reports. ${ }^{19}$ But what they do suggest is the need for caution, both in accepting the prevalent assumption of good health and wellbeing at this age, and in interpreting responses from, or about, the health of children.

We acknowledge the children, teachers, schools, nurse interviewers, and all those from the MRC Medical Sociology Unit involved in the 11 to 16 study. Thanks are also due to our colleagues and those members of the 11 to 16 study advisory committee who commented on an earlier draft: Geoff Der, Russell Ecob, Tony Glendinning, Kate Hunt, Lynn Hendry, Sally Macintyre, David Stone, and Lawrence Weaver. HS and PW are supported financially by the Medical Research Council of Great Supported

1 Vandervoorde J. Child health surveillance. Strasbourg: CounVandervoorde J. Child health surveillance. Stras

2 Bennett D. Young people and their health needs: a global perspective. Semin Adolesc Med 1985;1:1-14.

3 Woodroffe C, Glickman M, Barker M, Power C. Children, teenagers and health: the key data. Buckingham: Open University Press, 1993

4 Court D, Alberman E. Worlds apart. In: Forfar J, ed. Child health in a changing society. Oxford: Oxford University Press, 1988:1-30.

5 Forfar J. Changing paediatric perceptions and perspectives. In: Forfar J, ed. Child health in a changing society. Oxford: Oxford University Press, 1988:254-86.

6 Williams $\mathrm{H}, \mathrm{McNicol} \mathrm{K}$. Prevalence, natural history and relationship of wheezy bronchitis and asthma in children: an epidemiological study. BMF 1969;ii:321-5.

7 Kaplan B, Mascie-Taylor C. Biosocial factors in the epidemiology of childhood asthma in a British national epidemiology of childhood asthma in a British nationa
sample. F Epidemiol Community Health 1985;39:152-6.

8 Austin J, Russell G. Wheeze, cough, atopy and indoor envi-

8 Austin J, Russell G. Wheeze, cough, atopy and indoor envi-
ronment in the Scottish highlands. Arch Dis Child 1997;76: ronment 
9 Mortimer M, Kay J, Jaron A. Epidemiology of headache and childhood migraine in an urban general practice using ad 1992;34:1095-101.

10 Abu-Arafeh I, Russell G. Prevalence and clinical features of abdominal migraine compared with those of migraine headache. Arch Dis Child 1995;72:413-17.

11 Rewers M, LaPorte R, King H, Tuomilehto J. Trends in the prevalence and incidence of diabetes: insulin-dependent diabetes mellitus in childhood. World Health Stat $Q$ 1988;41:179-89.

12 Rowlands O, Singleton N, Maher J, Higgins V. Living in Britain: results from the 1995 general household survey. London: HMSO, 1997.

13 Royal College of General Practitioners, OPCS, DHSS. Morbidity statistics from general practice — third national study, 1981-82. London: HMSO, 1986.

14 Bone M, Meltzer $\mathrm{H}$. The prevalence of disability among children: OPCS surveys of disability in Great Britain, Report 3. children: OPCS surveys of dis

15 West P. Inequalities? Social class differences in health in British youth. Soc Sci Med 1988;27:291-6.

16 Sweeting H. Reversals in fortune? Sex differences in health in childhood and adolescence. Soc Sci Med 1995; 40:77-90.

17 Macfarlane A, Mitchell R. Health services for children and their relationship to the educational and social services. In Forfar J, ed. Child health in a changing society. Oxford: Oxford University Press, 1988:155-97.

18 Moore J. Self/proxy response status and survey response quality. $\mathcal{F}$ Official Stat $1988 ; 4: 155-72$.

19 Ecob R, Macintyre S, West P. Reporting by parents of longstanding illness in their adolescent children. Soc Sci Med 1993;36:1017-22.

20 Cunningham-Burley S, Maclean U. Dealing with children's illness: mother's dilemmas. In: Wyke S, Hewison J, eds. Child health matters. Milton Keynes: Open University Press, 1993:29-39.

21 Mechanic D, Newton M. Some problems in the analysis of morbidity data. $\mathcal{F}$ Chron Dis $1965 ; 18: 569-80$.

22 Kosa J, Alpert J, Haggerty R. On the reliability of family health information: a comparative study of mothers'
reports on illness and related behavior. Soc Sci Med 1967;1: reports oni $165-81$.

23 Mechanic D. The influence of mothers on their children's health attitudes and behavior. Pediatrics 1964;33:444-53.

24 Registrar General Scotland. Annual report for 1992 (report No 138). Edinburgh: General Register Office, 1993.

25 Ecob R, Sweeting H, West P, Mitchell R. The West of Scotland 11 to 16 study: schools, sample design and implementation issues. MRC Medical Sociology Unit Working paper No 53. Glasgow: Medical Sociology Unit, 1996.

26 Macintyre S, Hunt K, Sweeting H. Gender differences in health: are things as simple as they seem? Soc Sci Med 1996;42:617-24.

27 Thompson W, Walter S. A reappraisal of the kappa coefficient. 7 Clin Epidemiol 1988;41:949-58.
28 Feinstein A, Cicchetti D. High agreement but low kappa. I. The problems of two paradoxes. F Clin Epidemiol 1990;43: The probl

29 Altman D. Practical statistics for medical research. London: Chapman and Hall, 1991.

30 Landis J, Koch G. The measurement of observer agreement for categorical data. Biometrics 1977;33:159-74

31 West P, Sweeting H. Nae job, nae future: young people and health in a context of unemployment. Health and Social Care in the Community 1996;4:50-62.

32 Yunginger J, Reed C, O'Connell E, Melton J, O'Fallon M, Silverstein M. A community-based study of the epidemiology of asthma. Am Rev Respir Dis 1988;148:88-94.

33 Holgate S. What's causing the worldwide rise in asthma? MRC News 1994;63:20-3.

34 Dawson B, Horobin G, Illsley R, Mitchell R. A survey of childhood asthma in Aberdeen. Lancet 1969;i:827-30.

35 Calnan M, Peckham C. Incidence of insulin-dependent diabetes in the first sixteen years of life. Lancet 1977;i: 589-90.

36 Samanta A, Burden A, Jones G, et al. Prevalence of insulindependent diabetes mellitus in Asian children. Diabetic Med 1986;4:65-7.

37 Egermark-Eriksson I. Prevalence of headache in Swedish schoolchildren: a questionnaire survey. Acta Paediatr Scand 1982;71:135-40.

38 Wolff S. Psychiatric disorders of childhood. In: Kendell R, Zealley A, eds. Companion to psychiatric studies, 3rd ed. Edinburgh: Churchill Livingstone, 1983:439-68.

39 Polnay L, chair. Health needs of school age children: report of a joint working party. London: British Paediatric Association, 1995.

40 Rutter M, Smith D, eds. Psychosocial disorders in young people: time trends and their causes. Chichester: John Wiley, 1995.

41 Rutter M, Smith D. Towards causal explanations of time trends in psychosocial disorders of youth, In: Rutter M, Smith D, eds. Psychosocial disorders in young people: time
trends and their causes. Chichester: John Wiley, 1995:782trends

42 Sutherland E. A voice for the child: the Children (Scotland) Act 1995, Part 1. F Law Soc Scotland 1996;41:391-3.

43 Campbell A. Ethical issues in child health and disease. In: Forfar J, ed. Child health in a changing society. Oxford: Oxford University Press, 1988:215-53.

44 Scambler G. Epilepsy. London: Tavistock/Routledge, 1989.

45 Cartwright $\mathrm{A}$. The effect of obtaining information from different informants on a family morbidity inquiry. Appl Stat 1957;6:18-25

46 World Health Organisation. Constitution of the World Health Organisation. Geneva: WHO, 1947.

47 Cox A. Interviews with parents. In: Rutter M, Taylor E, Hersov L, eds. Child and adolescent psychiatry: modern approaches, 3rd ed. Oxford: Blackwell Scientific, 1994: 34-50. 